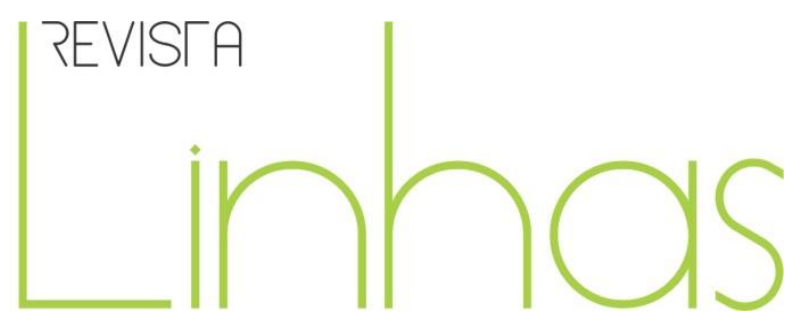

\title{
Educação literária em Portugal: os documentos oficiais, a voz e as práticas dos docentes ${ }^{1}$
}

\begin{abstract}
Resumo
O presente estudo pretende descrever, analisar e discutir como a Educação Literária está presente na escola, em Portugal, através dos documentos programáticos oficiais e das vozes e práticas dos docentes. O estudo aborda os documentos para a educação préescolar e para o $1 .^{\circ}$ ciclo do ensino básico. Os principais objetivos do estudo são: conhecer os documentos programáticos oficiais em relação à educação literária; compreender como esses documentos apresentam a educação literária; conhecer as conceções e as práticas dos docentes sobre a educação literária. Para este estudo convocámos uma metodologia assente na leitura crítica e reflexiva dos documentos e recorremos a vários estudos para conhecer as conceções e as práticas dos docentes. Os resultados do estudo permitem-nos concluir que a educação literária está presente nos documentos programáticos oficiais; todavia estes documentos nem sempre apontam práticas consentâneas com a promoção de uma verdadeira educação literária. Os docentes apresentam por vezes conceções pouco congruentes com o fomento de práticas que estimulem uma educação literária.
\end{abstract}

Palavras-chave: Educação Literária. Literatura. Escola. Educação PréEscolar. Ensino Básico.

\author{
Ângela Balça \\ Universidade de Évora - CIEC- \\ Portugal \\ apb@uevora.pt \\ Fernando Azevedo \\ Universidade do Minho - CIEC - \\ Portugal \\ fraga@ie.uminho.pt
}

\footnotetext{
Para citar este artigo:

BALÇA, Ângela; AZEVEDO, Fernando. Educação literária em Portugal: os documentos oficiais, a voz e as práticas dos docentes. Revista Linhas. Florianópolis, v. 18, n. 37, p. 131-153, maio/ago. 2017.
}

DOI: $10.5965 / 1984723818372017131$

http://dx.doi.org/10.5965/1984723818372017131

${ }^{1}$ Optou-se por manter a grafia da língua nativa (Língua Portuguesa - Portugal). 


\title{
Literary education in Portugal: curricular documents, the voice and practices of the teachers
}

\begin{abstract}
The present study aims to describe, analyse, and discuss the manner in which the Literary Education is present in the schools of Portugal, by taking the official program documents and the voices and practices of teachers into account. The study approaches the documents for pre-school and primary education. The main objectives are: to know the official programmatic documents related to literary education; to understand how these documents present literary education; to know the conceptions and practices of teachers in regard to literary education. For this study, we called for a methodology based on a critical and reflexive reading of the documents, and made use of several studies to apprehend the conceptions and practices of the teachers. The results allow us to conclude that literary education is present in the official program documents; however, these documents do not always point to practices that are consistent with the promotion of a true literary education. Teachers sometimes have conceptions that lack congruence with the promotion of practices that stimulate literary education.
\end{abstract}

Keywords: Literary Education. Literature. School. PreSchool Education. Primary Education. 


\section{Introdução}

A entrada da educação literária nos documentos programáticos oficiais, em Portugal, como um domínio autónomo e explícito, é relativamente recente. Muito embora a Literatura estivesse presente na sala de aula, mesmo quando falamos da educação pré-escolar e do $10^{\circ}$ ciclo do ensino básico (doravante $10^{\circ} \mathrm{CEB}$ ), ela não tinha grande visibilidade nos documentos programáticos oficiais para o $1 .^{\circ} \mathrm{CEB}$, no início do século XXI.

Vários fatores contribuíram certamente para que a educação literária tivesse uma outra visibilidade no jardim-de-infância e na escola. Dentre eles destacamos o desenvolvimento da investigação científica sobre as questões da promoção da leitura, da formação de leitores e da educação literária, a formação inicial e contínua dos docentes nestes temas, a generalização a todo o país da Rede de Bibliotecas Escolares e a implementação, desde 2006, do Plano Nacional de Leitura (doravante PNL).

A educação literária, segundo Azevedo e Balça,

visa dotar o leitor de um conhecimento relevante acerca de textos, autores, géneros, bem como convenções, temas e estilemas literários de modo a que ele se possa sentir membro ativo e participante de uma casa comum. (2016, p. 2)

Roig-Rechou (2013) refere que a educação literária busca dotar o leitor de um conjunto de saberes culturais, literários e sociais que o auxiliem a fertilizar não só a sua competência enciclopédica mas também a sua competência literária e intertextual (CERRILLO E SENÍS, 2005; CERRILLO, 2007a). A Literatura, pela sua capacidade de interrogar o mundo e de proporcionar outros modos de o pensar, constitui, como assinalou Gordon (2012), um precioso lugar que nos liberta da "caixa" em que, por vezes, nos sentimos aprisionados. Deste modo, e ainda de acordo com Azevedo e Balça, o

\footnotetext{
${ }^{2}$ Este trabalho foi financiado por Fundos Nacionais através da FCT (Fundação para a Ciência e a Tecnologia) e cofinanciado pelo Fundo Europeu de Desenvolvimento Regional (FEDER) através do COMPETE 2020 Programa Operacional Competitividade e Internacionalização ( $\mathrm{POCl}$ ) no âmbito do CIEC (Centro de Investigação em Estudos da Criança da Universidade do Minho) com a referência POCl-01-0145-FEDER007562.
} 
conceito de educação literária ultrapassa, assim, o nível do ensinoaprendizagem da literatura - o aprender a ler os textos como literários, obedecendo à convenção estética ou ao protocolo de ficcionalidade, ou o aprender a apreciar a literatura -, referindo-se ao desenvolvimento de competências que permitem ler o mundo de uma forma sofisticada e abrangente e contribuem para a formação de sujeitos críticos, capazes de ler e interrogar a praxis. (2016, p. 3)

Este é então o desafio que se coloca agora à escola, de forma obrigatória, no ensino básico. Mas a própria educação pré-escolar é mobilizada para este desígnio, iniciando as crianças mais pequenas na aventura da Literatura, do livro e da leitura.

Deste modo, o presente estudo tem como objetivos conhecer os documentos programáticos oficiais no que à educação literária diz respeito; compreender como esses documentos apresentam a educação literária; conhecer as conceções e as práticas dos docentes sobre a educação literária.

Assim, neste estudo, propomo-nos descrever, analisar e discutir, através de um trabalho de exegese sobre os textos, como a educação literária está presente nos documentos programáticos oficiais atuais. Por outro lado, tendo em conta estudos recentes, orientados por nós, damos conta da voz e das práticas dos docentes, no que à educação literária diz respeito, uma vez que estamos perante um domínio novo nos documentos programáticos oficiais do $1 .^{\circ} \mathrm{CEB}$, não esquecendo igualmente a educação pré-escolar.

\section{A educação literária nos documentos programáticos oficiais em Portugal}

Como afirmámos anteriormente, a educação literária, presente de forma expressa e independente, é um domínio algo recente, nos documentos programáticos oficiais, em Portugal. As Metas Curriculares de Português - Ensino Básico, do ano de 2012, apresentam, pela primeira vez, o domínio de Iniciação à Educação Literária, para o $10^{\circ}$ e $20^{\circ}$ ano de escolaridade e o domínio de Educação Literária, para o $3 .^{\circ}$ e $4 .^{\circ}$ ano. Estes domínios e designações mantêm-se no documento atual, que data de 2015, intitulado Programa e Metas Curriculares de Português do Ensino Básico (doravante PMCP). 
No documento orientador para a educação pré-escolar, Orientações Curriculares para a Educação Pré-Escolar (doravante OCEPE), de 2016, não encontramos nem esta área nem a designação educação literária. Todavia, uma análise atenta e mais profunda a este documento permite-nos perceber que a questão da educação literária se encontra plasmada tanto neste documento como no anterior (Orientações Curriculares para a Educação Pré-Escolar, do ano de 1997).

Sendo assim, o nosso olhar recai, em primeiro lugar, sobre o documento das OCEPE (2016). Este documento orientador, destinado ao trabalho na educação préescolar, encontra-se dividido por áreas de conteúdo. Para a área da língua materna e da literatura está destinado o conteúdo Área de Expressão e Comunicação. Nesta grande área, encontramos o Domínio da Linguagem Oral e da Abordagem à Escrita. Neste domínio, é visível a presença da Literatura, o apelo ao trabalho com a Literatura e pressente-se a mobilização para o fomento da educação literária nas crianças mais pequenas.

Assim, a narração de histórias, o contacto com a poesia e com as formas poéticas de fundo tradicional, como as rimas, as lengalengas, os trava-línguas e as adivinhas são aspetos referidos nas OCEPE (2016). A Literatura, muito particularmente a Literatura Tradicional, possibilita às crianças a construção de uma identidade, de um imaginário que “permite-lhes sentirem-se pertença de um determinado universo, daquele e não de outro, partilhando ideias, valores, sentimentos, formas de ser, formas de estar, formas de ler o mundo." (BALÇA, 2015, p. 29). A Literatura será, portanto, indispensável para a construção da competência literária e da competência enciclopédica da criança.

Muito embora no documento se refira que estes textos poéticos de fundo tradicional são válidos para o trabalho ao nível da consciência linguística, também se alerta para a sua mais-valia para a exploração lúdica da linguagem ou para o prazer em lidar com as palavras - "Ouve atentamente histórias, rimas, poesias e outros textos, mostrando prazer e satisfação." (OCEPE, 2016, p. 72). E, na verdade, a dimensão lúdica e de prazer, gerada pela leitura dos textos literários, é um dos caminhos muito importantes para a promoção de uma educação literária.

No que respeita à poesia, o documento alerta explicitamente os educadores de infância para o facto de estarmos perante um texto literário que dá um contributo para a 
sensibilização estética das crianças. Este aspeto é muitíssimo relevante, dado que é das raras referências, no documento, que mostram o entendimento da Literatura, neste caso da poesia, na sua vertente estética. Ora a educação literária visa a formação do leitor que encara a Literatura como uma Arte, sendo capaz de entender e integrar a sua dimensão estética. Na verdade, de acordo com Phùng e Fendler (2015, p. 177), “Literature belongs to 'language arts'”, a Literatura é uma forma de Arte distinta que trabalha com a palavra.

Sendo assim, faz-se um alerta aos educadores de infância, afirmando-se no documento que aprendizagens neste domínio são promovidas quando este profissional “Disponibiliza livros e material de leitura de qualidade tanto no seu conteúdo como do ponto de vista estético." (OCEPE, 2016, p. 72), mencionando-se, de modo explícito, os livros de literatura para a infância.

Todavia, como afirma Teresa Colomer, numa entrevista concedida a Mello (2015), na promoção da educação literária há a necessidade de combinar a experiência individual perante uma obra literária com o domínio das convenções da comunicação literária que permitirão ao leitor aceder ao texto literário na sua plenitude,

Así, pues, el objetivo de la educación literaria se formula como el desarrollo de la competencia en esta forma específica de lectura e implica un aprendizaje que asocie indisolublemente la implicación del lector y el dominio de las convenciones. (MELLO, 2015, p. 319)

Se até este momento percebemos que o documento das OCEPE (2016) aposta nesta implicação do leitor com os textos literários, chamando a atenção para as questões lúdicas, afetivas, de prazer e estéticas em redor da receção da Literatura, podemos também encontrar, neste mesmo documento, a mobilização para o trabalho sobre a comunicação literária e sobre as convenções que regem esta receção do texto literário. Deste modo, assinala-se a necessidade da compreensão da funcionalidade, das especificidades e da estrutura organizativa dos textos escritos, onde entra naturalmente o texto literário, referindo-se que esta é uma responsabilidade do educador de infância. A tónica é já colocada no trabalho com as crianças em redor da organização, da estrutura, da apresentação dos textos. De facto, a receção do texto literário, por parte das crianças, 
não é automática ou natural, ela requer um processo educativo, como afirma Costa (2015).

Entre as muitas sugestões de reflexão para estes profissionais, disponibilizadas no documento, realçamos aquelas que remetem para o fomento da educação literária nas crianças:

Quando lê para as crianças, considera que é um bom modelo, evidenciando e transmitindo-lhes o prazer e a satisfação que sente no momento? Os momentos de leitura de histórias são agradáveis e sentidos como positivos? (OCEPE, 2016, p. 74)

Em síntese, estas pistas de reflexão conduzem os educadores de infância para o clima de prazer, afeto, motivação que tem de presidir a todas as estratégias e atividades planificadas em redor da leitura, para o fomento de uma verdadeira educação literária.

Deste documento para a educação pré-escolar passamos para a análise e discussão do documento PMCP (2015), acompanhando a saída das crianças do jardim-deinfância e a sua entrada no $1 .{ }^{\circ} \mathrm{CEB}$.

$\mathrm{Na}$ verdade, assinalamos desde já uma enorme perplexidade na leitura do documento PMCP (2015). Neste texto, surge-nos a designação Iniciação à Educação Literária, denominação que consideramos incompreensível. De facto, como assinalámos anteriormente, o trabalho com a promoção da educação literária inicia-se na educação pré-escolar, estando isto também já plasmado no documento das Orientações Curriculares de 1997. Quando as crianças chegam ao 1. $\mathrm{CEB}$, o seu contacto com a Literatura, com a sua receção, com as convenções que regem a obra literária é uma efetiva realidade. As crianças, de um modo geral, durante a educação pré-escolar, ouviram histórias com satisfação e com prazer, criaram laços de afeto com o livro, travaram conhecimento com o vocabulário e construíram um entendimento sobre a funcionalidade, a especificidade e as convenções que regem o texto literário. Deste modo, quando as crianças entram no $10^{\circ} \mathrm{CEB}$, não estamos perante uma iniciação à educação literária; estamos diante de uma continuação de um trabalho que foi, na generalidade, eficazmente desenvolvido pelos educadores de infância com as crianças. 
Os objetivos do documento PMCP (2015) ajudam-nos a entender como a Literatura e como a educação literária são perspetivadas neste ciclo de ensino. Sobre estas temáticas em particular centram-se os objetivos número 14, 15 e 16.

O objetivo 14 "Interpretar textos orais e escritos, de expressão literária e não literária, de modalidades gradualmente mais complexas" (PMCP, 2015, p. 5) não se centra exclusivamente nos textos literários e coloca a sua tónica quer num processo gradativo de complexidade no contacto com os textos quer na capacidade dos alunos para a interpretação destes mesmos textos. Todavia, esta associação entre texto literário e texto não literário não salvaguarda, quanto a nós, as estratégias de leitura e de compreensão específicas na receção da Literatura.

“Interpretar textos literários de diferentes géneros e graus de complexidade, com vista à construção de um conhecimento sobre a literatura e a cultura portuguesas, valorizando-as enquanto património de uma comunidade." (PMCP, 2015, p. 5) é o objetivo 15 que se centra agora somente nos textos literários e faz apelo a uma interpretação que potencie a construção de conhecimento sobre Literatura e Cultura, na vertente patrimonial. Vertente muito valorizada pela escola, ela assume uma importância relevante na construção de uma identidade nacional e patrimonial que também caracteriza qualquer língua materna. Porém, esta dimensão patrimonial não poderá ser a única abordagem consentida ao texto literário, sob pena de serem restringidas ou mesmo esquecidas outras dimensões do mesmo, tal como afirmam Balça e Costa (2017).

O objetivo 16 "Apreciar criticamente a dimensão estética dos textos literários, portugueses e estrangeiros, e o modo como manifestam experiências e valores." (PMCP, 2015, p. 5) remete para uma das dimensões da educação literária, ou seja, a capacidade da Literatura contribuir para a fruição e para a educação estética das crianças, possibilitando o desenvolvimento de uma dimensão ético-axiológica ao relacionarem-se com os textos. Salientamos a possibilidade do contacto das crianças com obras literárias estrangeiras, para a construção não só dessa dimensão ético-axiológica mas também para a construção de uma ampla leitura do mundo.

Na realidade, pensamos que, de um modo geral, estes objetivos nos remetem para a promoção de uma educação literária, uma vez que contemplam a cognição e a fruição, dois aspetos evidenciados por Teresa Colomer na leitura literária, na entrevista concedida 
a Mello (2015), já por nós referida: “Esta manera de leer fusiona la participación subjetiva y emocional del lector, con la recepción distanciada de la obra a partir de procedimientos de análisis e interpretación.” (MELLO, 2015, p. 319).

No ponto intitulado Caracterização, inserido no PMCP (2015), complementa-se a conceção de educação literária, subjacente ao documento, e já patente nos seus objetivos:

O domínio da Educação Literária (... vem dar mais consistência e sentido ao ensino da língua, fortalecendo a associação curricular da formação de leitores com a matriz cultural e de cidadania. Ouvir ler e ler textos de literatura infantil é um percurso que conduz ao objetivo prioritário de compreensão de textos e é um estímulo à apreciação estética. $O$ contacto com textos literários, portugueses e estrangeiros, em prosa e em verso, de distintos géneros, e com textos do património oral português, amplia o espectro de leituras e favorece a interação discursiva e o enriquecimento da comunicação. (PMCP, 2015, p. 8)

Neste ponto Caracterização, destacamos o reconhecimento de que a educação literária confere ao ensino da língua portuguesa uma maior solidez, percebendo-se que o trabalho com a Literatura contribui, em diversos âmbitos, para uma maior competência e um melhor desempenho dos alunos na atualização da sua língua materna.

A educação literária possibilita assim, de acordo com o documento em estudo, uma junção no currículo entre a formação de leitores e a assunção da Literatura como promotora da matriz cultural e de cidadania de um povo. Aguiar e Silva (2007) chama a atenção para o facto de o lexema Literatura remeter para um "corpus em geral de textos literários, o de conjunto da produção literária de um determinado país" (AGUIAR E SILVA, 2007 , p. 6), assumindo-se como um fator que contribui para o desenvolvimento, nos alunos, desta matriz cultural e de cidadania. Neste sentido, podemos falar da formação de leitores, com uma mais vasta competência enciclopédica, dotados de uma mais consistente dimensão ético-axiológica, promovidas com o contacto efetivo com os textos literários. E é neste contacto com as obras literárias que os alunos vão enriquecer a sua competência literária, uma vez que ampliam o seu espectro de leituras.

A dimensão estética da Literatura e a sua valorização no processo de educação literária são, de novo, convocadas. E este parece-nos ser um aspeto de suma importância, 
dado que a escola tem muita dificuldade em encarar a Literatura como uma forma de Arte, sendo esta uma questão, de acordo com Phùng e Fendler (2015), tradicional, uma vez que a Literatura é considerada como um campo diferente das Artes na estrutura do currículo escolar, mesmo pela OCDE "The arts outlined in the OECD report include music, visual arts, theatre, dance and multi-arts. Literature (...) is not usually named among the arts in arts education."(PHÙNG; FENDLER, 2015, p. 177).

A promoção de uma educação literária visa sempre a formação de leitores e de leitores literários. A reação individual perante uma obra literária, valorizada por Mendoza Fillola (2004), Roig-Rechou (2009), Souza, Girotto e Silva (2012), Costa (2015) ou Balça e Costa (2017) é uma das chaves para o fomento da educação literária. O aluno tem de participar de forma ativa e eficaz no processo de receção do texto literário, do modo a que "sepa reconocer las peculiaridades del discurso literario y seguir las instrucciones de recepción que el mismo texto incluye." (MENDOZA FILLOLA, 2004, p. 64).

Este processo de receção da obra literária, de modo individual, pleno, exige uma relação entre o texto e o leitor que Souza, Girotto e Silva (2012) consideram necessária para a compreensão da leitura. Ora esta compreensão da leitura de textos literários vai permitir ao aluno o enriquecimento da interação discursiva e da comunicação.

Embora a educação literária promova a primazia do individual, na escolha e na receção da obra literária, o PMCP (2015) apresenta uma lista de obras a serem integradas no currículo a nível nacional, no total de "sete títulos por ano de escolaridade" (PMCP, 2015, p. 8), aduzindo o argumento de que "a escola, a fim de não reproduzir diferenças socioculturais exteriores, assume um currículo mínimo comum de obras literárias de referência" (PMCP, 2015, p. 8). Apesar de sermos sensíveis a este argumento, que ainda assim pode ser discutido, consideramos sete títulos excessivo, tendo em conta o tempo disponível para o fomento deste domínio na sala de aula e a imperiosa necessidade de se ler por prazer, não compatível com as escolhas de obras literárias de outros.

A tentativa de minorar este contrassenso é remetida para a leitura autónoma, a ser promovida pelo professor e pelo professor-bibliotecário, tendo como sugestão as listas de livros do PNL, considerando agora as escolhas pessoais dos alunos. Porém, estas escolhas individuais restringem-se às listas de livros do PNL e isto está muito bem explícito no documento programático, no conteúdo Educação Literária, para os 4 anos de 
escolaridade no $1 .{ }^{\circ} \mathrm{CEB}$, onde nos surge a "Leitura e Audição. Obras de literatura para a infância, textos da tradição popular (Lista em Anexo); outros textos literários selecionados pelo aluno, sob orientação (Listagem PNL)" (PMCP, 2015, p. 17).

Consideramos ser este o enorme desafio que se coloca à promoção da educação literária na escola. Se por um lado deveríamos ter o primado do indivíduo, das suas escolhas, das suas interpretações, da sua receção do texto literário, por outro lado os decisores políticos pensam que só a normalização pode contribuir para um currículo único que supostamente colocará todos os alunos em igualdade. E esta deriva uniformizadora continua nas metas a atingir, apresentadas pelo PMCP (2015).

Dada a extensão das metas curriculares (PMCP, 2015) para a educação literária, optámos apenas por nos debruçar sobre aqueles aspetos que se centram sobre o desafio, mencionado anteriormente, dado que já observámos como o documento programático apresenta reservas em relação à primazia das leituras individuais. Nestas metas curriculares (PMCP, 2015), na generalidade, deparamo-nos com objetivos e categorias “(...) que nos parecem relevantes na promoção da educação literária: compreensão leitora; apreciação dos textos; leitura como processo de relação pessoal com os objetos textuais; relação entre leitura e criatividade." (COSTA, 2015, p. 27), tal como este investigador tinha salientado já para as metas curriculares do documento programático de 2012.

Apesar disso, destacamos que todos os objetivos enunciados nas metas curriculares (PMCP, 2015), relacionados com a audição e/ou a leitura e a compreensão de textos literários referem explicitamente que esses textos deverão ser os da lista em anexo ao documento programático ou os das listas do PNL. De facto, fecha-se aqui, claramente, a possibilidade de uma verdadeira partilha de leituras, escolhidas em total liberdade, pelos alunos. Promover a educação literária, quanto a nós, é também permitir a entrada na sala de aula e a partilha, entre alunos e docente, das leituras livres de todos sem exceção.

A expressão e manifestação de sentimentos, opiniões, pontos de vista sobre as obras literárias "Manifestar sentimentos, ideias e pontos de vista suscitados pelas histórias ouvidas." (PMCP, 2015, p. 56) é uma das metas a atingir, que remete para a reação individual perante o texto literário. Porém, a apresentação dessas leituras a todo o 
grupo, com a obrigatoriedade de justificar a sua eleição e de as aconselhar, "Apresentar à turma livros lidos, justificando a escolha e recomendando a sua leitura." (PMCP, 2015, p. 56), já nos parece, de novo, uma intromissão neste primado do individual. A liberdade de não apresentar leituras, não justificar a eleição de uma determinada obra ou mesmo de não a recomendar tem de ser um direito adquirido por parte dos leitores, mesmo daqueles que estão em formação.

Para finalizarmos esta análise e discussão do documento PMCP (2015), manifestamos a nossa preocupação em relação a algumas metas propostas para o objetivo "Compreender o essencial dos textos escutados e lidos. (v. Lista em Anexo)" (PMCP, 2015, p. 61). A comunicação literária exige o domínio das convenções do texto literário, como vemos explícito no documento programático, quando se refere a obrigação de trabalhar com os alunos aspetos como as personagens, o tempo, o espaço, a ação. Todavia, os docentes não podem restringir o seu trabalho sobre a Literatura a estes aspetos de natureza estrutural, como tantas vezes sucede, não só pelo contágio com os manuais escolares como também por uma certa tradição e imobilismo nas práticas pedagógicas. A nossa inquietação torna-se maior quando vemos para o trabalho com a poesia esta meta bem explícita "Reconhecer características essenciais do texto poético: estrofe, verso, rima e sonoridades." (PMCP, 2015, p. 61). No objetivo, referido anteriormente, nada mais encontramos, de forma explícita, para o trabalho com a poesia, podendo nós, ainda assim, interpretar que a meta "Interpretar sentidos da linguagem figurada." (PMCP, 2015, p. 61) possa ser mobilizada para o estudo do texto poético. Uma vez que vários estudos (SOUZA, 2006; CERRILLO, 2007b; RIBEIRO, 2009; MELO, 2011; SOARES, 2012; ANDRICAÍN E ORLANDO RODRÍGUEZ, 2016) concluíram que o texto poético na escola é relegado para um segundo plano, consideramos que o documento programático não contribui para a valorização da poesia, enquanto forma literária fundamental no fomento da educação literária.

Em síntese, o documento programático PMCP (2015) apresenta, de um modo geral, categorias, objetivos e metas que permitem o fomento de uma educação literária na escola. Contudo, esta promoção da educação literária fica certamente algo comprometida com a deriva normalizadora na escolha das obras para audição/leitura e 
com a menor valorização do primado do individual na relação estabelecida com a Literatura.

\section{A voz e as práticas dos docentes}

Dada esta entrada explícita e autónoma da educação literária nos documentos oficiais programáticos, é nossa intenção, neste artigo, ouvir a voz e as práticas dos professores de $1 .^{\circ} \mathrm{CEB}$, mas também dos educadores de infância, à volta desta questão. Para tal socorremo-nos de alguns estudos, orientados por nós, que revelam a voz e algumas práticas destes docentes. Porém, não podemos deixar de ressalvar que nos encontramos perante uma aproximação à realidade, dado que estamos diante de estudos parcelares que não podem de modo nenhum ser generalizados. Ainda assim consideramo-los válidos para integrarem este artigo. O conhecimento constrói-se também destes pequenos passos na investigação.

Os estudos, convocados para este artigo, realizaram-se no âmbito da Prática de Ensino Supervisionada dos educadores/professores-investigadores e mobilizaram a metodologia da investigação-ação. Por isso mesmo, são estudos que partem de uma investigação sobre a voz e as práticas do orientador cooperante, para depois melhor situarem a ação do educador/professor-investigador, uma vez que de acordo com ZuberSkerrit, citado em Coutinho, Sousa, Dias, Bessa, Ferreira e Vieira (2009, p. 363),

fazer Investigação-Ação implica planear, atuar, observar e refletir mais cuidadosamente do que aquilo que se faz no dia-a-dia, no sentido de introduzir melhorias nas práticas e um melhor conhecimento dos práticos acerca das suas práticas.

Começamos, então, por nos concentrar na voz e nas práticas dos educadores de infância. A investigação-ação, desenvolvida por Vitória (2016), centrou-se na Hora do Conto (ALBUQUERQUE, 2000; GIROTTO E LIMA, 2006; VELOSO, 2001). Na verdade, a Hora do Conto é uma prática que julgamos fundamental para a promoção de uma educação literária junto das crianças. De acordo com Veloso (2001), a Hora do Conto é "uma das formas mais impressivas de cativar a criança e estabelecer com ela as 
cumplicidades necessárias a uma semiose literária" (VELOSO, 2001, p. 4). Consideramos que é nesta Hora do Conto que se inicia o fomento de uma educação literária, pela possibilidade de diálogo individual entre a criança, o texto e a sua consciência:

A gratuitidade do momento [Hora do Conto] não permite que se tirem dividendos de qualquer natureza, seja plástica, dramática ou hermenêutica - deixem a criança em diálogo com a sua consciência, com a sua imaginação, com as suas angústias e medos, com os seus afectos. (VELOSO, 2001, p. 4)

Na sua investigação, Vitória (2016) socorreu-se da entrevista semi-estruturada, tendo questionado a educadora, responsável pela sala, sobre a Hora do Conto. Nas respostas, esta profissional referiu que realizava a Hora do Conto diariamente, com as crianças em grande grupo, sendo este momento objeto de planificação. Este momento da Hora do Conto seria sempre realizado após o lanche da tarde das crianças e acontecia normalmente no mesmo espaço, dedicado ao trabalho em grande grupo, designado “local de reunião". A educadora de infância afirmou ainda que as crianças já percebiam a importância deste momento na rotina diária.

No decorrer da sua investigação, Vitória (2016, p. 64) confirmou que "as crianças já estavam habituadas a este momento diário e sabiam apreciá-lo de forma silenciosa e atenta", sendo o espaço dedicado à Hora do Conto ideal, "bastante amplo, permitia que as crianças se sentassem confortavelmente no chão e que as mesmas tivessem um contacto direto com o contador e com as restantes crianças" (VITÓRIA, 2016, p. 64).

No seu estudo, Vitória (2016) mencionou também que esta educadora de infância referiu que lia histórias adequadas à faixa etária das crianças, utilizando o objeto livro e recorrendo à animação da leitura, através de fantoches, sombras chinesas ou meios audiovisuais, como por exemplo o computador.

Em resposta à questão se a Hora do Conto era apreciada pelas crianças, a educadora de infância replicou que era 
muito apreciada pelas crianças desde tenra idade (...) e explicita que estas o demonstram permanecendo em silêncio e por norma atentas enquanto decorre a hora do conto... também percebo isso através das questões que colocam no final das histórias (VITÓRIA, 2016, p. 65)

Apesar destas boas práticas, sabemos que a promoção de uma educação literária tem ainda um caminho a percorrer na educação pré-escolar. A investigação-ação desenvolvida por Santana (2016), centrada na promoção do livro e da leitura, mostra-nos uma realidade pouco consentânea com um fomento eficaz da educação literária.

Assim, na sua investigação, Santana (2016) utilizou também a entrevista semiestruturada. Nas suas respostas, a educadora de infância, responsável pela sala, mencionou que a leitura faz parte integrante do seu dia-a-dia. Contudo, a observação participante permitiu a esta educadora-investigadora perceber que "durante o período de observação e intervenção, não constatei que a leitura fosse parte integral do dia das crianças, considerando que existiam poucos momentos de leitura" (SANTANA, 2016, p.76). Na verdade, na sua investigação, Santana (2016) constatou um desfasamento entre a conceção e a voz da educadora de infância cooperante, em relação à promoção da leitura e de uma educação literária, e as suas práticas reais. Deste modo, esta educadora de infância realizava a Hora do Conto apenas uma vez na semana, o que consideramos manifestamente pouco. Quando as crianças traziam livros de casa, caso a educadora de infância considerasse que havia tempo, esses livros eram lidos na sala. Portanto, atentamos que estas práticas encerram dois problemas no fomento da educação literária. Estes problemas prendem-se com a reduzida presença da Hora do Conto nesta sala, dado que a promoção da leitura, do gosto pela leitura, da relação entre o texto e o leitor tem de ser diária, tem de ser sentida como uma rotina boa, agradável, por parte das crianças, que não se compadece com pouco tempo; já a não leitura de livros trazidos de casa pelas crianças vai certamente frustrar as expetativas das mesmas e esta atitude não concorre, com certeza, para a aproximação da criança ao livro e à leitura.

Em relação à seleção das histórias a ler às crianças, segundo Santana (2016), o primeiro critério elegido pela educadora de infância é o seu gosto pessoal pela história. Estando cientes da importância do mediador de leitura gostar das histórias que lê/conta às crianças, concordamos com Santana (2016, p. 77), quando afirmou que este "não deve 
ser o único critério que devemos ter em conta". De facto, ao gosto pessoal do mediador de leitura deverá juntar-se, entre outras coisas, o gosto das crianças, os seus interesses, a sua faixa etária e a sua maturidade. No entanto, há a referir que a educadora de infância mencionou que tinha em conta, na eleição das obras, as ilustrações, que deveriam ser apelativas e o texto em si, que deveria ser interessante.

Em relação às visitas à biblioteca escolar, ponto de referência fundamental no fomento de uma educação literária, Santana (2016, p. 76) referiu que "no período de observação e intervenção apenas existiram duas idas à biblioteca". De notar que no espaço deste jardim-de-infância há uma biblioteca escolar e que a intervençãoinvestigação teve a duração de 4 meses.

A investigação-ação desenvolvida por Henriques (2015), centrada no contacto e na relação das crianças da educação pré-escolar com o livro, revela igualmente dados interessantes sobre a promoção de uma educação literária nestes contextos. Esta intervenção-investigação decorreu em duas salas de uma instituição de educação préescolar.

Assim, Henriques (2015) constatou que as educadoras de infância, responsáveis pelas salas, liam para as crianças e acediam aos seus pedidos para ouvirem histórias. Todavia, a Educadora 1 (doravante E1) lia para as crianças todos os dias; a Educadora 2 (doravante E2) lia apenas duas vezes na semana. Ambas as educadoras de infância referiram que as crianças tinham liberdade total para mexerem nos livros presentes na sala e apresentavam já comportamentos leitores, como fazerem leituras icónicas e contarem as histórias para as restantes crianças. Em relação às crianças mais novas, da E1, são relatados comportamentos como rasgar, levar os livros à boca ou morder/comer os livros. Estes comportamentos são esperados em faixas etárias mais pequenas ( 1 a 3 anos) e cabe aos profissionais trabalhar com as crianças o manuseamento e o cuidado a ter com os livros, para que elas evoluam para o desenvolvimento de comportamentos leitores adequados. Todos estes aspetos são muito importantes para o fomento de uma educação literária, que passa também pelo reconhecimento do valor e pelo afeto estabelecido com o objeto livro.

As duas educadoras de infância afirmaram que levavam as crianças à biblioteca da instituição, sendo que a E1 refere que vai semanalmente enquanto que a E2 menciona que 
vai todos os dias. Nestas idas à biblioteca, as crianças ouvem ler histórias pelos adultos. Ambas as profissionais referem que as crianças só podem manusear os livros da biblioteca sob a supervisão do adulto; os livros não são de livre e total acesso e não estão ao seu alcance "Ou pedem-nos para ir buscar os livros, ou vão buscar cadeiras e sobemnas de modo a alcançar os livros. Há também casos em que tentam subir às estantes." (HENRIQUES, 2015, p. 81). Estas declarações da E1, subscritas pela E2, revelam-nos como estas crianças aderem aos livros e são seduzidas por eles; exibem como estas crianças já começaram a criar uma relação de prazer, de afeto, de proximidade com os livros; mostram como com estas crianças se iniciou o longo processo do fomento da educação literária. Por outro lado, estes testemunhos dão-nos conta de uma gestão desastrosa desta biblioteca no que ao acesso, manuseamento do livro e consequente promoção de uma educação literária diz respeito.

De seguida, iremos concentrar-nos na voz e nas práticas dos professores de $1 .^{\circ}$ CEB. De novo, damos voz à investigação-ação desenvolvida por Vitória (2016), sobre a Hora do Conto, mas agora em contexto de $1 .{ }^{\circ}$ CEB. Igualmente, neste contexto, um dos instrumentos para a recolha de dados foi a entrevista semi-estruturada à professora, responsável pela sala de aula. Nas respostas à entrevista, esta professora afirmou que valorizava e que se interessava bastante pela Hora do Conto e pela questão da animação da leitura. Contudo, o que este estudo revela, sobre a voz e as práticas desta professora, é uma enorme preocupação com o tempo disponível para a Hora do Conto, numa luta feroz entre o programa oficial para cumprir, entre os exames a que os alunos seriam sujeitos no final do ano letivo e entre a necessidade, eventualmente sentida, para haver espaço e tempo para atividades de leitura recreativa. E, como iremos observar, tudo foi condicionado, neste caso, pela sensação de falta de tempo e pela falta de capacidade de reflexão sobre a organização da prática pedagógica, num não entendimento dos benefícios para os alunos da Hora do Conto, nas mais diversas dimensões cognitivas, ético-axiológicas, estéticas, lúdicas.

Deste modo, a Hora do Conto, prática que a professora-investigadora implementou, era realizada na sala de aula, mas sem que houvesse uma arrumação específica do espaço para tal, 
Durante a prática, infelizmente, não consegui afastar as mesas e cadeiras para a hora do conto, uma vez que implicava muito tempo e distraía os alunos na arrumação das mesmas. (...) os alunos permaneciam sentados nos seus devidos lugares durante a hora do conto. (VITÓRIA, 2016, p. 67)

Em relação ao tempo para a Hora do Conto, a professora-investigadora mencionou que "só me foi disponibilizada meia hora e uma vez por semana" (VITÓRIA, 2016, p. 67). A professora, responsável pela sala, afirmou que utilizava duas horas por semana para a Hora do Conto, todavia a professora-investigadora considerou que este momento não acontecia efetivamente, dado que ele era utilizado para a leitura das obras, impostas pelos documentos programáticos e através de fichas/guiões de leitura já preparados para tal. Aliás, a própria professora referiu que nesta altura, "só lê os livros propostos pelo Plano Nacional de Leitura e pelas metas curriculares" (VITÓRIA, 2016, p. 67). Ainda assim, este momento dedicado à leitura era apreciado pelas crianças "fazendo-me lembrar sempre que hoje é o dia da história/conto... dizendo: hoje já trouxemos os nossos livros para ler, professora!" (VITÓRIA, 2016, p. 67).

Do mesmo modo, o estudo de Santana (2016), centrado na promoção do livro e da leitura, foi também realizado no contexto de $1 .{ }^{\circ} \mathrm{CEB}$ e, de novo, se socorreu da entrevista semi-estruturada para a recolha de dados. A professora, responsável pela sala, afirmou, nas respostas à entrevista, ter muito interesse pelas questões da promoção e da animação da leitura, dizendo que procurava adequar o espaço da biblioteca da sala aos momentos de leitura recreativa, utilizando mantas no chão para as crianças se sentarem e um fantocheiro de grandes dimensões. Todavia, a professora-investigadora, durante os cerca de 4 meses que durou a sua prática, observou que em nenhuma ocasião o espaço da biblioteca da sala foi utilizado para momentos de leitura.

Ainda assim, os momentos de leitura recreativa aconteciam nesta sala, fora do espaço mencionado, a pedido dos alunos ou quando eles traziam livros de casa. A professora-investigadora implementou um momento de rotina diária, para a leitura de histórias, justamente antes do começar das atividades na sala de aula. A visita à biblioteca escolar, para ouvir histórias, era frequente, em resposta aos convites semanais da própria biblioteca escolar. As obras literárias trabalhadas na sala de aula eram as obras impostas pelos documentos programáticos e algumas escolhidas, pela professora, do Plano 
Nacional de Leitura, havendo, apesar disto, espaço, como mencionámos anteriormente, para os livros que as crianças traziam espontaneamente de casa.

Em síntese, notamos, nestes estudos, algumas contradições entre a voz e a prática dos docentes, no que à educação literária diz respeito. Se a leitura e o livro são valorizados, não nos parece que haja um entendimento profundo do conceito de educação literária. E este não entendimento revela-se nas práticas destes profissionais, nem sempre congruentes com o fomento de uma educação literária, tanto no espaço sala/sala de aula como no espaço biblioteca escolar.

\section{Considerações finais}

A educação literária, como é explicitamente afirmado pelos documentos curriculares oficiais do $1.0^{\circ} \mathrm{CEB}$, constitui um saber relevante na construção do sujeito como pessoa capaz de ler o mundo de forma sofisticada e abrangente (CERRILLO, 2007a). Ainda que aquilo que é dito, nesses documentos, não corresponda exatamente aquilo que, como investigadores desta área, os autores deste artigo gostariam de ver plasmado, não podemos deixar de sublinhar a importância e a pertinência de este conceito integrar atualmente o normativo curricular oficial português do $10^{\circ}$ CEB e de estar já subentendido no documento orientador para a educação pré-escolar.

O olhar à voz dos educadores de infância e dos professores do $1 .{ }^{\circ}$ CEB permitiu-nos constatar que, apesar de os profissionais, no terreno, defenderem, em termos teóricos, a relevância da promoção do livro, da leitura e da educação literária, a observação das suas práticas mostra-nos uma realidade pouco consentânea com um fomento eficaz da educação literária. Desde um entendimento não adequado do funcionamento de uma biblioteca escolar até à incapacidade em perceber os benefícios para os alunos da Hora do Conto, nas mais diversas dimensões cognitivas, ético-axiológicas, estéticas e lúdicas, passando por uma "adaptação" da filosofia do Plano Nacional de Leitura a processos de transformação curricular, que expurgam a leitura literária da liberdade de escolha e da liberdade de o leitor não falar acerca daquilo que leu (PENNAC, 1997), o que as práticas dos profissionais, alvo destas investigações-ações, demonstram é que existe uma elevada dificuldade em concretizar, em contexto de prática pedagógica, os princípios da 
educação literária. De novo, realçamos que estes dados não poderão ser generalizados. Contudo, também a nossa experiência como investigadores e formadores de educadores de infância e professores do $10^{\circ} \mathrm{CEB}$ permite-nos considera-los válidos para a construção de conhecimento nesta área.

Como nota conclusiva, apontamos a necessidade de reforçar decisivamente a formação contínua de educadores de infância e professores do $10^{\circ}$ CEB no que toca ao conceito de educação literária e às estratégias metodologicamente adequadas e cientificamente fundamentadas por forma a que a escola, no seu todo, possa, de facto, formar leitores, isto é, sujeitos capazes de ler o mundo de um modo amplo, sofisticado e abrangente.

\section{Referências}

AGUIAR E SILVA, Vítor Manuel. Teoria da Literatura. Coimbra: Livraria Almedina, 2007.

ALBUQUERQUE, Fátima. A Hora do conto: reflexões sobre a arte de contar histórias na escola. Santa Maria da Feira: Editoral Teorema, 2000.

ANDRICAÍN, Sérgio; ORLANDO RODRÍGUEZ, António. Escuela y Poesía ¿Y qué hago con el poema? Cuenca: Ediciones de la Universidad de Castilla-La Mancha, 2016.

AZEVEDO, Fernando; BALÇA, Ângela. Educação literária e formação de leitores. In: AZEVEDO, Fernando; BALÇA, Ângela (Org.). Leitura e educação literária. Lisboa: Pactor, 2016, p. 1-13.

BALÇA, Ângela. Contos Tradicionais: Língua, Cultura e Imaginário. In: AZEVEDO, Fernando (Org.). Literatura Infantil e Imaginário. Braga: Centro de Investigação em Estudos da Criança / Instituto de Educação, 2015, p. 29-41. 
BALÇA, Ângela; COSTA, Paulo. Leitura e educação literaria: da viagem possível às restrições do mapa. Ensino em Re-Vista, v. 24, n. 1, jan./jul. 2017. (no prelo).

\section{CERRILLO, Pedro. Literatura Infantil y Juvenil y Educación Literaria. Hacia una nueva} enseñanza de la literatura. Barcelona: Octaedro, 2007a.

CERRILO, Pedro. El archivo de la memoria. El Cancionero Infantil en la escuela. Educación y Biblioteca, v. 160, p. 78-81, 2007b. Disponível em:

<http://gredos.usal.es/jspui/bitstream/10366/119372/1/EB19_N160_P78-81.pdf>. Acesso em: 25 jan. 2017.

CERRILLO, Pedro; SENÍS, Juan. Nuevos tiempos, ¿nuevos lectores? Ocnos, n. 1, p. 19-33, 2005. Disponível em: <http://www.revista.uclm.es/index.php/ocnos/article/view/166/147>. Acesso em: 25 jan. 2017.

COSTA, Paulo. Algumas notas sobre o discurso oficial para o Português: as Metas Curriculares e a educação literária. Nuances: Estudos sobre Educação, v. 26, n. 3, p. 17-33, set/dez 2015. Disponível em:

<http://revista.fct.unesp.br/index.php/Nuances/article/viewFile/3691/3145>. Acesso em: 06 jan. 2017.

COUTINHO, Clara; SOUSA, Adão; DIAS, Anabela; BESSA, Fátima; FERREIRA, Maria; VIEIRA, Sandra. Investigação-Acção: Metodologia preferencial nas práticas educativas. Psicologia, Educação e Cultura, v. XIII, n. 2, p.355-379, 2009. Disponível em: <http://repositorium.sdum.uminho.pt/bitstream/1822/10148/1/Investiga\%C3\%A7\% 3\%A30_AC\%C3\%A7\%C3\%A30_Metodologias.PDF>. Acesso em: 30 jan. 2017.

GIROTTO, Cyntia; LIMA, Elieuza. A hora do conto no processo de aprendizagem da leitura e da escrita. Nuances: Estudos sobre Educação, v. 13, n. 14, p.61-81, jan/dez 2006. Disponível em:

<revista.fct.unesp.br/index.php/Nuances/article/download/370/405>. Acesso em: 30 jan. 2017.

GORDON, José. El efecto imaginante. Cuauhtémoc: Dirección General de Publicaciones del Consejo Nacional para la Cultura y las Artes, 2012. Disponível em: <http://blogs.fad.unam.mx/asignatura/fidencio_lopez/wp-content/uploads/2014/02/Elefecto-imaginante.pdf>. Acesso em: 26 jan. 2017.

HENRIQUES, Daniela. Prática de Ensino Supervisionada em Educação Pré-Escolar: Como se caracteriza o contacto das crianças com os livros em contexto pré-escolar? Évora: Universidade de Évora, 2015.

MELLO, Cláudio. Entrevista a Teresa Colomer sobre Educación Literaria. Via Atlântica, n. 28, dez. 2015. Disponível em:

<http://www.revistas.usp.br/viaatlantica/article/view/100870/107097>. Acesso em: 26 jan. 2017. 
MELO, Isabel. Da poesia ao desenvolvimento da competência literária : propostas metodológicas e didáticas para o ensino-aprendizagem da língua portuguesa nos $1 .^{\circ} \mathrm{e} 2 .^{\circ}$ ciclos do ensino básico. Braga: Instituto de Educação, Universidade do Minho, 2011.

MENDOZA FILLOLA, António. La educación literaria. Bases para la formación de la competencia lecto-literaria. Málaga: Ediciones Aljibe, 2004.

METAS CURRICULARES DE PORTUGUÊS - ENSINO BÁSICO. Lisboa: Ministério da Educação e Ciência, 2012. Disponível em:

<http://static.publico.pt/docs/educacao/MetasPortugues.pdf>. Acesso em: 27 jan. 2017.

OCEPE. Orientações curriculares para a Educação Pré-escolar. Lisboa. Ministério da Educação, 1997. Disponível em:

$<$ https://www.dge.mec.pt/sites/default/files/Basico/orientacoes_curriculares_pre_escolar. pdf>. Acesso em: 27 jan. 2017.

OCEPE. Orientações curriculares para a Educação Pré-escolar. Lisboa: Ministério da Educação, 2016. Disponível em: <http://www.dge.mec.pt/ocepe/>. Acesso em: 27 jan. 2017. PENNAC, Daniel. Como um romance. 9. ${ }^{\mathrm{a}}$ ed . Porto: ASA, 1997.

PHÙNG, Thanh; Fendler, Lynn. A critique of knowledge-based arts education: ars gratia artis through rancière's aesthetics. SISYPHUS. Journal of Education, v. 3, n. 1, p. 172-191, 2015. Disponível em: <http://revistas.rcaap.pt/sisyphus/article/view/7724/5408>. Acesso em: 27 jan. 2017.

PMCP. Programa e Metas Curriculares de Português do Ensino Básico. Lisboa: Ministério da Educação e Ciência, 2015. Disponível em:

<https://www.dge.mec.pt/sites/default/files/Basico/Metas/Portugues/pmcpeb_julho_2015. pdf >. Acesso em: 30 jan. 2017.

RIBEIRO, João Manuel. A Poesia no Primeiro Ciclo do Ensino Básico: das Orientações Curriculares às decisões dos docentes. Coimbra: Universidade de Coimbra, 2009.

ROIG-RECHOU, Blanca-Ana. Educación literaria e historias literarias. In: DÍAZ, Esther Corral; SURIS, Lydia Fontoira; MATO, Eduardo Moscoso (Org.). A mi dizen quantos amigos hey. Homenaxe ao Professor Xosé Luís Couceiro. Santiago de Compostela: Universidade de Santiago de Compostela, 2009, p. 333-342.

ROIG-RECHOU, Blanca-Ana. Educação literária e Literatura Infantojuvernil. s/c: Editora Tropelias \& Companhia, 2013.

SANTANA, Sara. Prática de Ensino Supervisionada na Educação Pré-Escolar e Ensino do 1. ${ }^{\circ}$ Ciclo do Ensino Básico - A promoção do livro e da leitura na Educação Pré-Escolar e 1. ${ }^{\circ}$ Ciclo do Ensino Básico. Évora: Universidade de Évora, 2016. 
SOARES, Ana. A (Re)descoberta da poesia na formação de leitores. Braga: Instituto de Educação, Universidade do Minho, 2012.

SOUZA, Renata Junqueira. A poesia no contexto escolar - sons e rimas formando leitores. In: AZEVEDO, Fernando (Coord.). Língua materna e literatura infantil. Elementos nucleares para professores do ensino básico. Lisboa: Lidel, 2006, p. 47-54.

SOUZA, Renata Junqueira; GIROTTO, Cyntia; SILVA, Joice. Educação literária e formação de leitores: da leitura em si para leitura para si. Ensino em Re-Vista, v. 19, n. 1, jan/jun, 2012. Disponível em: <http://www.seer.ufu.br/index.php/emrevista/article/viewFile/14914/8410>. Acesso em: 30 jan. 2017.

VELOSO, Rui Marques. Curtir Literatura Infantil no Jardim de Infância. 2001. Disponível em: <http://magnetesrvk.no-

ip.org/casadaleitura/portalbeta/bo/documentos/ot_li_jardinf_rveloso_a.pdf >. Acesso em: 30 jan. 2017.

VITÓRIA, Daniela. Prática de Ensino Supervisionada na Educação Pré-Escolar e Ensino do 1. ${ }^{\circ}$ Ciclo do Ensino Básico - A Hora do Conto: Relato de Práticas. Évora: Universidade de Évora, 2016. 